was more common in women with RA, but did not differ significantly between pregnancies prior to and after RA diagnosis.

A total of $41 \%$ of the post-RA pregnancies had an adverse pregnancy outcome (miscarriage, preterm delivery, or infant abnormality), compared to $13 \%$ of pre-RA pregnancies $(p=0.01)$ and $20 \%$ of control pregnancies $(p=0.01)$.

\begin{tabular}{|c|cc|cc}
\hline & $\begin{array}{c}\text { Pregnancies in } \\
\text { Healthy controls }\end{array}$ & $\begin{array}{c}\text { Pregnancies in } \\
\text { women with RA }\end{array}$ & $\begin{array}{c}\text { Pregnancies } \\
\text { prior to RA }\end{array}$ & $\begin{array}{c}\text { Pregnancies } \\
\text { after RA }\end{array}$ \\
\hline Number of Pregnancies & 99 & 76 & 32 & 44 \\
Live Births & $53(54 \%)$ & $51(67 \%)$ & $20(63 \%)$ & $31(70 \%)$ \\
Spontaneous Abortion & $13(13 \%)$ & $15(20 \%)$ & $4(13 \%)$ & $11(25 \%)$ \\
Ectopic Pregnancies & $3(3 \%)$ & $3(4 \%)$ & $2(6 \%)$ & $1(2 \%)$ \\
Elective Termination & $30(30 \%)$ & $7(9 \%)^{\dagger}$ & $6(19 \%)$ & $1(2 \%)$ \\
Preterm Birth & $6 / 53(11 \%)$ & $5 / 51(10 \%)$ & 0 & $5 / 31(16 \%)$ \\
Preeclampsia & $1 / 53(2 \%)$ & $9 / 51(18 \%)^{\dagger}$ & $5 / 20(25 \%)$ & $4 / 31(13 \%)$ \\
C-section & $14 / 52(27 \%)$ & $15 / 51(29 \%)$ & $7 / 20(35 \%)$ & $8 / 31(26 \%)$ \\
Abnormal Infant & $3 / 54(6 \%)^{*}$ & $3 / 51(6 \%)$ & 0 & $3 / 31(10 \%)$ \\
Adverse Pregnancy & $20(20 \%)$ & $22(29 \%)$ & $4(13 \%)$ & $18(41 \%) \neq$ \\
Outcome & & & & \\
\hline
\end{tabular}

*one twin pregnancy in controls

t $p<0.05$, controls vs. RA pregnancies

$\pm \mathrm{p}<0.05$, pre-vs, post-RA pregnancies

Conclusions: Women with RA, overall, had similar rates of miscarriage, stillbirth, and ectopic pregnancy compared to healthy women, but pregnancies that occurred after RA diagnosis had higher rates of these adverse outcomes. More pregnancies in women with RA were planned, leading to a lower rate of elective termination.

Acknowledgements: This study was funded by Pfizer.

Disclosure of Interest: M. Clowse Grant/research support from: Pfizer, Janssen, Consultant for: UCB, G. McDaniel: None declared, A. Eudy: None declared DOI: 10.1136/annrheumdis-2017-eular.6338

\section{SAT0120 EVALUATION OF THE RISK OF OVERALL MALIGNANCY AND MALIGNANT LYMPHOMA WITH METHOTREXATE AND BIOLOGICAL AGENTS IN PATIENTS WITH RHEUMATOID ARTHRITIS BASED ON THE IORRA COHORT DURING A 14-YEAR OBSERVATION PERIOD}

N. Sugimoto ${ }^{1}$, E. Tanaka ${ }^{1}$, E. Inoue ${ }^{1,2}$, M. Kawano ${ }^{1}$, M. Ochiai ${ }^{1}$, Y. Shimizu ${ }^{1}$, R. Yamaguchi ${ }^{1}$, K. Ikari ${ }^{1}$, A. Nakajima ${ }^{1}$, A. Taniguchi ${ }^{1}$, H. Yamanaka ${ }^{1} .{ }^{1}$ Institute of Rheumatology, Tokyo Women's Medical University; ${ }^{2}$ Center for Clinical Research for Development, National Center for Child Health and Development, Tokyo, Japan

Background: While dramatic progress has been made in this decade with treatments for rheumatoid arthritis (RA), such as methotrexate (MTX) and biological agents, concern about the safety, including the occurrence of malignancy, of these highly effective drugs still exists in daily clinical practice. There has not been an evident association between the use of biological agents and the occurrence of malignancy in most reports from clinical trials ${ }^{1}$ and observational studies ${ }^{2}$, although MTX use might be associated with the development of malignant lymphoma, called MTX-associated lymphoproliferative disorder ${ }^{3}$, in patients with RA. In an analysis of risk factors for overall and site-specific malignancies in Japanese patients with RA, higher disease activity was identified to be a risk factor for overall malignancies (hazard ratio $[\mathrm{HR}] 1.10,95 \% \mathrm{Cl} 1.02-1.19$ ), suggesting that tight control of RA disease activity would reduce the occurrence of malignancies in patients with $\mathrm{RA}^{4}$. However, the risk of malignancies with RA treatments including MTX and biological agents was not assessed in that analysis.

Objectives: We investigated the association between the occurrence of malignancies (overall and malignant lymphoma) and drug use (MTX and biological agents) in a large observational cohort of Japanese patients with RA over a long-term period.

Methods: Among Japanese patients with RA enrolled in the Institute of Rheumatology, Rheumatoid Arthritis (IORRA) cohort from April 2000 to September 2013, data for all malignancies were extracted from patients' self-reports and confirmed by medical records. Data for malignancies occurring in patients who dropped out of the IORRA study during the subsequent three months were also collected from medical information from affiliated hospitals. We analysed whether MTX and biological agents were risk factors for overall malignancy and malignant lymphoma using a marginal structural Cox proportional hazards model ${ }^{5}$ adjusted for age, gender, smoking history, body mass index, RA disease duration, rheumatoid factor positivity and disease activity (28-joint disease activity score).

Results: Among 11,106 Japanese patients with RA representing 68,483 personyears, 507 overall malignancies, including 68 malignant lymphomas, were confirmed. Neither MTX nor biological agent use was a significant risk factor for overall malignancy, with an $\mathrm{HR}(95 \% \mathrm{Cl})$ of $1.18(0.77-1.81)$ and $1.01(0.65-1.57)$, respectively, or for malignant lymphoma, with an $\mathrm{HR}(95 \% \mathrm{Cl})$ of $1.17(0.55-2.48)$ and $1.26(0.43-3.64)$, respectively.

Conclusions: The use of MTX and biological agents was not significantly associated with the occurrence of overall malignancy or malignant lymphoma during long-term longitudinal observation of Japanese patients with RA.

References:

[1] Moulis G, et al. PLoS One. 2012;7:e48991.

[2] Mariette X, et al. Ann Rheum Dis. 2011;70:1895-904.

[3] Kameda T, et al. Arthritis Care Res (Hoboken). 2014;66:1302-9.
[4] Sugimoto N, et al. EULAR Congress 2016;FRI0143.

[5] Choi HK, et al. Lancet. 2002;359:1173-7.

Disclosure of Interest: N. Sugimoto Speakers bureau: Takeda Pharmaceutical and Bristol Myers Squibb., E. Tanaka Consultant for: Abbvie, Eisai Pharmaceutical, Chugai Pharmaceutical, Bristol Myers Squibb, Astellas Pharmaceutical, Pfizer, Takeda Pharmaceutical, and Ayumi Pharmaceutical., Speakers bureau: Abbvie, Eisai Pharmaceutical, Chugai Pharmaceutical, Bristol Myers Squibb, Astellas Pharmaceutical, Pfizer, Takeda Pharmaceutical, and Ayumi Pharmaceutical., E. Inoue: None declared, M. Kawano: None declared, M. Ochiai: None declared, Y. Shimizu: None declared, R. Yamaguchi: None declared, K. Ikari Grant/research support from: Astellas, UCB, Bristol-Meyers, Pfizer, Eisai, Tanabe-Mitsubishi, Chugai, AbbVie, Janssen Pharmaceutical, Otsuka, Kaken, Asahi-Kasei, Hisamitsu and Takeda., Speakers bureau: Astellas, UCB, Bristol-Meyers, Pfizer, Eisai, Tanabe-Mitsubishi, Chugai, AbbVie, Janssen Pharmaceutical, Otsuka, Kaken, Asahi-Kasei, Hisamitsu and Takeda., A. Nakajima Consultant for: Bristol-Meyers, Mitsubishi Tanabe Pharma, Nippon Kayaku Co. Ltd., Novartis Pharma, Pfizer, Siemens Healthcare Diagnostics K.K. and Takeda Pharmaceutical Company., Speakers bureau: Bristol-Meyers, Mitsubishi Tanabe Pharma, Nippon Kayaku Co. Ltd., Novartis Pharma, Pfizer, Siemens Healthcare Diagnostics K.K. and Takeda Pharmaceutical Company., A. Taniguchi Grant/research support from: AbbVie, Eisai, Takeda, Tanabe-Mitsubishi, Teijin Pharma, Pfizer., Speakers bureau: AbbVie, Eisai, Takeda, Tanabe-Mitsubishi, Teijin Pharma, Pfizer., H. Yamanaka Grant/research support from: MSD, Ayumi, AbbVie, Eisai, Ono, Astellas, DaiichiSankyo, Taisyo-Toyama, Takeda, Tanabe-Mitsubishi, Chugai, Teijin Pharma, Torii, Nippon Shinyaku, Pfizer. UCB. Nippon Kayaku, YL biologics, Bayer and BristolMeyers., Consultant for: MSD, Ayumi, AbbVie, Eisai, Ono, Astellas, Daiichi-Sankyo, Taisyo-Toyama, Takeda, Tanabe-Mitsubishi, Chugai, Teijin Pharma, Torii, Nippon Shinyaku, Pfizer. UCB. Nippon Kayaku, YL biologics, Bayer and Bristol-Meyers., Speakers bureau: MSD, Ayumi, AbbVie, Eisai, Ono, Astellas, Daiichi-Sankyo, Taisyo-Toyama, Takeda, Tanabe-Mitsubishi, Chugai, Teijin Pharma, Torii, Nippon Shinyaku, Pfizer. UCB. Nippon Kayaku, YL biologics, Bayer and Bristol-Meyers. DOI: 10.1136/annrheumdis-2017-eular.2663

\section{SAT0121 COMORBITIES AND DISEASE ACTIVITY ARE RELEVANT FOR FUNCTIONAL DISABILITY IN RHEUMATOID ARTHRITIS}

N. Andrade ${ }^{1}$, A.M. Kakehasi ${ }^{2}$, C. Machado ${ }^{2}$, K. Gomes ${ }^{3}$, M.F. Guimarães ${ }^{2}$, S. Krampe ${ }^{1}$, C. Rodrigues ${ }^{3}$, C. Brenol ${ }^{1}{ }^{1}{ }^{1}$ Federal University of Rio Grande do Sul, Porto Alegre; ${ }^{2}$ Universidade Federal de Minas Gerais, Belo Horizonte; ${ }^{3}$ University of Fortaleza, Fortaleza, Brazil

Background: Health status in rheumatoid arthritis (RA), as measured by Health Assessment Questionnaire - Disability Index (HAQ-DI), has been established as a relevant quantitative measure to assess and monitor the disease (1). Current RA therapy has shown improvement in patient-reported outcomes, but more data on specific factors influencing health status are needed (2).

Objectives: To assess the relationship between functional disability and clinical factors in patients with RA, using the HAQ score.

Methods: Cross-sectional study in patients with RA according to the ACR classification criteria from three Brazilian University Hospitals. Demographic and comprehensive clinical data, including components of metabolic profile were collected. Blood pressure, weight and height were determined in the assessment visit and recent laboratory data were assessed from medical records. Disease activity was evaluated by the Disease Activity Score in 28 joints (DAS28) and functional disability was assessed by the HAQ-DI, considering an index $>0.5$ as disability. All analyses were performed using Stata for MAC 12.0 software. Variables that achieved a $p$-value $<0.3$ in the univariate analysis were considered as candidates to take part of a multivariate binomial logistic model, and in this model, variables were considered as statistically significant at the 0.05 significance level (3).

Results: 453 patients were included, $380(83.9 \%)$ women, mean age 55.7 $( \pm 12)$ years, $356(79.1 \%)$ Caucasian, and mean disease duration of $13.3( \pm 9)$ years. Methotrexate were used by $73.5 \%$ of the sample. Mean DAS28 was 3.9 $( \pm 1.4)$, mean $\mathrm{HAQ}$ score was $1.11( \pm 0.77)$, and $23.9 \%$ of the patients had $\mathrm{HAQ}$ score $>0.5$. Dyslipidemia, diabetes mellitus (DM), high blood pressure (HBP) and family history of premature cardiovascular disease occurred in $28.6 \%, 12.8 \%$, $51 \%$ and $21.4 \%$ of the patients, respectively. Mean body mass index (BMI) was $27.1( \pm 4.9) \mathrm{kg} / \mathrm{m}^{2}$. In multivariate analysis age, DAS28, tobacco use, and diabetes mellitus were independently associated with $\mathrm{HAQ}>0.5$ (TABLE 1).

Table 1. Association between clinical parameters, disease activity, and functional disability (HAQ $>0.5)$

\begin{tabular}{lcc}
\hline Parameters & OR $($ IC95\%) & $\mathrm{p}$ \\
\hline Age & $1.01(1.01 ; 1.03)$ & $<0.001$ \\
DAS28 & $2.74(1.69 ; 4,45)$ & $<0.001$ \\
Tobacco use & $1.37(1.06 ; 1.77)$ & 0.016 \\
Diabetes Mellitus & $1.83(1.82 ; 1.83)$ & $<0.001$ \\
\hline
\end{tabular}

DAS28 - disease activity score in 28 joints; BMI - body mass index; OR - odds ratio.

Conclusions: Our results depicted that distinct factors could reflect in the functional status response in RA patients. This is relevant since it may influence the clinicaly important difference when evaluating the HAQ response in populations with diverse cultural features and different comorbidities prevalence. 


\section{References:}

[1] Fries JF, Spitz P, Kraines RG, Holamn HR: Measurement of patient outcome in arthritis. Arthritis Rheum 1980; 23: 137-45.

[2] Pincus T. Are Patient Questionnaire Scores as "Scientific" as Laboratory Tests for Rheumatology Clinical Care? Bull NYU Hosp Jt Dis. 2010;68(2):130-139.

[3] Bursac Z, Gauss CH, Williams DK, Hosmer DW. Purposeful selection of variables in logistic regression. Source Code for Biology and Medicine. 2008;3:17. doi:10.1186/1751-0473-3-17.

Disclosure of Interest: None declared

DOI: 10.1136/annrheumdis-2017-eular.5544

\section{SAT0122 WHICH MULTIMORBID CONDITIONS ARE MORE PREVALENT AROUND THE TIME OF EARLY RA DIAGNOSIS AND HAVE THE GREATEST IMPACT ON TRAJECTORIES OF DISEASE ACTIVITY IN THE FIRST YEAR? RESULTS FROM THE CANADIAN EARLY ARTHRITIS COHORT}

O. Schieir ${ }^{1}$, S.J. Bartlett 2,3 , C. Hitchon ${ }^{4}$, J. Pope ${ }^{5}$, G. Boire ${ }^{6}$, B. Haraoui ${ }^{7}$, E. Keystone ${ }^{1}$, D. Tin $^{8}$, C. Thorne ${ }^{8}$, V.P. Bykerk ${ }^{1,9}$ on behalf of Canadian Early Arthritis Cohort Canada (CATCH) Investigators. ${ }^{1}$ University of Toronto, Toronto; ${ }^{2}$ McGill University, Montreal, Canada; ${ }^{3}$ Johns Hopkins University, Baltimore, United States: ${ }^{4}$ University of Manitoba, Winnipeg; ${ }^{5}$ Western University, London; ${ }^{6}$ Universite de Sherbrooke, Sherbrooke; ${ }^{7}$ Institut de Rhumatologie de Montreal, Montreal; ${ }^{8}$ Southlake Regional Health Center, Newmarket, Canada; ${ }^{9}$ Hospital for Special Surgery, New York, United States

Background: Multimorbidity (MM) is highly prevalent in early RA (ERA), and higher counts of conditions are associated with poorer disease control ${ }^{1}$. It is important to understand the number of, and which specific conditions most affect disease presentation, early therapies and disease activity over time.

Objectives: To estimate the prevalence of MM conditions at the time of ERA diagnosis and associations with ERA clinical characteristics, early treatment, and trajectory of disease activity in the 1st year of follow up.

Methods: Data were from ERA patients (<1-year of symptoms) enrolled in CATCH (Canadian Early Arthritis Cohort) who met 1987 or 2010 RA criteria, and had at least two DAS28 measures in the first year. We examined baseline prevalence of: 1) cardiovascular disease (CVD), 2) diabetes, 3) cancer, 4) pulmonary disease, 5) bowel disease, 6) other rheumatic diseases, and 7) psoriasis, obtained from patient-reports of physician-diagnosed medical conditions, 8) obesity $(\mathrm{BMI} \geq 30)$, and 9 ) depressive symptoms (RAND-12 $<42$ ). We compared baseline demographic and clinical characteristics in ERA + each condition vs. ERA alone. We estimated adjusted effects of each condition on early use of RA therapies with logistic regression and adjusted effects of each condition on DAS28 trajectory over the first year of follow up with linear growth models.

Results: The sample included 1,595 patients, $1153(72 \%)$ were female, with a mean (sd) age of 54 (15) years and 6 (3) months of symptoms. At baseline 1,434 $(92 \%)$ were treated with conventional DMARDs (mostly methotrexate $(76 \%)$ ) and $33(2 \%)$ with a biologic. More than $70 \%$ of ERA patients reported at least one MM, and over $30 \%$ reported 2+ MMs. Patients with MM were often older and had higher disease activity at baseline, with variations by condition. Patients with RA+CVD or depressive symptoms had a $60 \%$ and $90 \%$ higher adjusted odds of baseline steroid use, respectively $(p<.001)$. In fully adjusted growth models, relative to patients with ERA only, patients with: a) diabetes, other rheumatic diseases or depressive symptoms had higher baseline DAS28 scores and less improvement over time, b) pulmonary disease, bowel disease, psoriasis or obesity had similar baseline DAS28 scores but less improvement over time; and c) CVD or cancer had higher baseline DAS28 scores but similar improvement over time (all $\mathrm{p}<0.05$ ).

Conclusions: Multimorbidity is common in ERA patients seen in routine practice and associated with higher disease activity at baseline, less improvement over time, or both, and a greater likelihood of prescribing steroids for certain conditions. Integrating MM in to current RA care strategies may help achieve better patient outcomes.

\section{.}

[1] Hitchon CA, et al. Self-reported comorbidity is common in early inflammatory arthritis and associated with poorer function and worse arthritis disease outcomes: results from the Canadian Early Arthritis Cohort. Rheumatology. 2016. doi: $10.1093 /$ rheumatology/kew061

Disclosure of Interest: O. Schieir: None declared, S. Bartlett Consultant for: UCB, Pfizer, C. Hitchon: None declared, J. Pope Grant/research support from: Amgen, BMS, Pfizer, Roche, UCB, Consultant for: AbbVie, Actelion, Amgen, Bayer, BMS, Genzyme, Hospira, Lilly, Merck, Norvartis, Pfizer, Regeneron, Roche, Sanofi, UCB, G. Boire: None declared, B. Haraoui Grant/research support from: AbbVie, Amgen, BMS, Janssen, Pfizer, Roche and UCB, Consultant for: AbbVie, Amgen, BMS, Celgene, Eli Lilly Janssen, Merck, Pfizer, Roche and UCB, Speakers bureau: Amgen,BMS Janssen, Pfizer and UCB, E. Keystone Grant/research support from: Abbott Laboratories, Amgen Inc, AstraZeneca Pharmaceuticals LP, Bristol-Myers Squibb, F.Hoffmann-La Roche Inc, Janssen Inc, Lilly Pharmaceuticals, Novartis Pharmaceuticals, Pfizer Pharmaceuticals, Sanofi-Aventis, UCB, Consultant for: Abbott Laboratories, AstraZeneca Pharma, Biotest, Bristol-Myers Squibb Company, Crescendo Bioscience, F Hoffmann-La Roche Inc, Genentech Inc, Janssen Inc, Lilly Pharmaceuticals,Merck, Pfizer Pharmaceuticals, UCB, Speakers bureau: Abbott Laboratories, AstraZeneca LP,
Adjusted^ effects of multimorbid conditions on trajectory of DAS28 over the first year of follow up in patients with

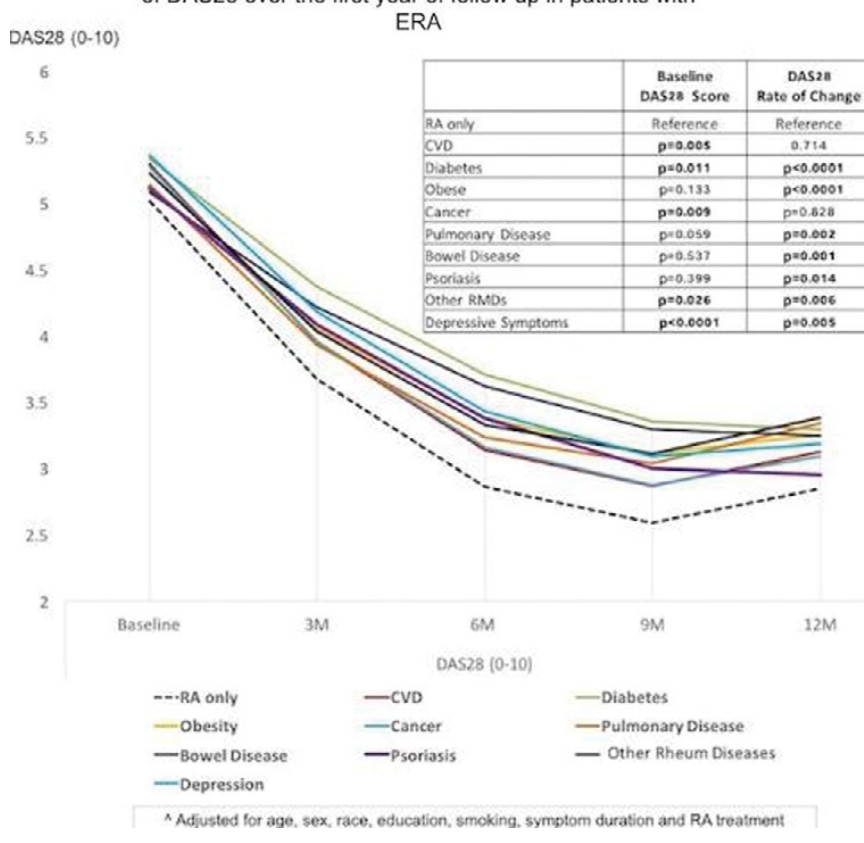

Bristol-Myers Squibb Canada, F Hoffmann-La Roche Inc, Janssen Inc, Pfizer Pharmaceuticals, UCB,Amgen, D. Tin: None declared, C. Thorne: None declared, V. Bykerk: None declared

DOI: 10.1136/annrheumdis-2017-eular.6369

\section{SAT0123 MULTIDIMENSIONAL EVALUATION OF PAIN IN RHEUMATOID ARTHRITIS}

P. Vergne-Salle ${ }^{1}$, S. Pouplin ${ }^{2}$, A. Bera-Louville ${ }^{3}$, M. Soubrier ${ }^{4}$, C. Richez ${ }^{5}$, R.-M. Javier ${ }^{6}$, S. Perrot ${ }^{7}$, P. Bertin ${ }^{1} .{ }^{1}$ Rheumatology, University Hospital, Limoges; ${ }^{2}$ Rheumatology, University Hospital, Rouen; ${ }^{3}$ Rheumatology, University Hospital, Lille; ${ }^{4}$ Rheumatology, University Hospital, Clermont-Ferrand;

${ }^{5}$ Rheumatology, University Hospital, Bordeaux; ${ }^{6}$ Rheumatology, University Hospital, Strasbourg: ${ }^{7}$ Pain center, University Hospital, Paris, France

Background: Although pain in rheumatoid arthritis (RA) is frequently thought to be inflammatory in nature, some studies reported clinically significant pain despite relatively low rheumatoid arthritis (RA) disease activity. Less than $50 \%$ of patients are satisfied by the management of pain.

Objectives: to report a recent multidimensional evaluation of pain in a large RA population.

Methods: Patients with RA were enrolled in 7 French Rheumatology Centers during a visit or a hospitalization in a transversal observational study. Sociodemographic data, previous and prescribed medications, disease duration, immunologic status, DAS28 score were assessed. Patients completed the multidimensional pain questionnaire from french health autority, the health assessment questionnaire ( $\mathrm{HAQ})$, the Beck depression scale and the anxiety scale STAI. Joint damage was evaluated by a simple erosion narrowing score.

Results: Of the 299 screened patients, 295 were included with a mean age of $58.4 \pm 11.7$ years, $80.3 \%$ of female, a mean disease duration of $13.2 \pm 9.6$ years, positivity of rheumatoid factors in $76.4 \%$, anti-citrullin antibodies in $74 \%$ of cases. Concerning medications, $42.7 \%$ were treated by corticoids (mean dose $=6.4 \mathrm{mg} / \mathrm{d}), 66 \%$ by analgesic drugs $(64.1 \%$ with acetaminophen, $45.6 \%$ weak opioids, $7.1 \%$ strong opioids) and $24.4 \%$ with NSAIDs. The RA treatments were DMARDs in $69.1 \%$ and biotherapies in $82.7 \%$ of cases. The mean DAS- 28 score was $3.1 \pm 1.3$ with $38.7 \%$ of patients in remission and $15.4 \%$ in low disease activity. The verbal scale for satisfaction about pain management showed that a third of patients was very satisfied, the half satisfied, $16 \%$ weakly or not satisfied. The mean pain visual analogic scale (VAS) for the last 8 days was $33.6 \mathrm{~mm} \pm 26.5 / 100$. $39 \%$ of patients had a pain VAS $>40 \mathrm{~mm} / 100$. The Beck scale showed a moderate to severe depression in $34,3 \%$ of patients. Anxiety was present in $57.5 \%$. The impacts of pain on daily behaviors were more important on work. The pain VAS for the 8 days was correlated with the score of depression et with the DAS-28 score $(p<0.0001)$. The population with a pain VAS $>40 \mathrm{~mm}$ had a significant more important Beck score, anxiety score, HAQ, DAS-28 score and had more impacts of pain on daily behaviors There was no association between pain and structural damage and disease duration. There was no difference between the populations with VAS $>40$ or $<40 \mathrm{~mm}$ in terms of IL-6, IL-17 and IL-33 serum levels. The multidimensional evaluation of pain wasn't different between treatement groups (DMARDs, biotherapies) and between the different biotherapies. Multivariate analysis with principal component analysis 